that spent on all energy research will increase from $36 \%$ in 1977 to $45 \%$ in 1981. Of the $£ 57 \mathrm{~m}$ spent on energy $\mathrm{R} \& \mathrm{D}$ in $1978, £ 30 \mathrm{~m}$ is being spent on nuclear energy. Holland contributes $£ 14 \mathrm{~m}$ to the EEC energy research programme of which about $£ 10 \mathrm{~m}$ is spent on nuclear research.
Before the budget was published at the start of the new parliamentary year, the ministry for science policy announced that the Science Information Bureau will become permanent and be expanded slightly. It has been operating on a trial period for two years at the Academy of Sciences. And at a meeting of the special parliamentary committee for science policy at the end of October, the minister announced the setting up of a group of experts to study the effect of microelectronics, especially microprocessors, on society. The group should report within three months. Casper Schuuring

\title{
Poland tries the taste of space
}

\section{During 1978, three cosmonauts from Eastern Europe visited the Soviet Salyut-6 orbiting space station. Vera Rich talks to the Polish cosmonaut, Miroslaw Hermaszewski in Warsaw}

Miroslaw Hermaszewski, like his two brothers, is a pilot by profession, not a scientist. However as a cosmonaut he was obliged to fulfil a dual role-crew member and scientific worker. In the latter capacity Hermaszewski was responsible especially for space medicine, which he describes as "a Polish speciality".

The medical programme concentrated on two experiments: "kardiolider" and "smak". The first monitored the cardiovascular system "to determine the potentialities of the heart in space and also during pre-flight training". This, Hermaszewski told me, meant that "from the psychological point of view we felt very safe, knowing our hearts were being constantly monitored, especially when we were not in contact with Earth". (Constant contact, he explained, is not maintained as a rule, although Soviet ships around the world are on constant emergency watch.)

The second medical experiment "smak" (Polish for "taste") was designed by the Academy of Military Aviation Medicine to monitor sensory changes under conditions of weightlessness. A few days before take-off, the cosmonauts sampled various menus and chose those they wished to take into orbit. "We chose the meals we preferred" said Hermaszewski "but after a few days in space we didn't like them. This means that our sense of taste had changed."

Challenged that the falling off of appreciation could be due to deterioration of the rations and/or boredom, Hermaszewski explained that the meals were specially prepared to preserve quality and taste, and also that there was "a menu-cycle of six days". "And even then, it wasn't exactly the same meal", he added. "I mean, if on one day we had, say, barszcz and turkey at one meal, then six days later we'd have barszcz and turkey again, but not at the same meal." The scientific team who worked out the experiments had, he said, developed a numerical method of estimating taste, which allowed the activity of the tastebuds to be monitored quantitatively.
Both "smak" and "kardiolider", added Hermaszewski, were important for medicine in general. Versions of kardiolider were now being produced for use in post-coronary rehabilitation programmes, while "smak" could provide valuable data about sensory processes.

With the third main Polish experiment, 'Syrena', Hermaszewski clearly felt his responsibilities considerably. Although he worked in the experiment with the Soviet cosmonaut, Ivanchenkov-one of the long-stay Soviet crew -he was aware that the experiment had been developed by Polish scientists. "It was absolutely Polish from the beginning, and was called 'Syrena' after the symbol of Warsaw". He admitted that during the running of the experiment which took 5 to 6 hours each time, he kept getting up at night to check the equipment (apparently quite unnecessarily).

'Syrena' was in fact an experimental capsule, used in conjunction with the Soviet 'splav' furnace, to produce highly homogeneous tellurium cadmium and telkurium/mercury alloys. Such molecular weights, are of considerable interest in semiconductor technology, and, in fact, both the Czech and East German cosmonauts carried out analogous experiments. It appears from Hermaszewski's description, however, that although the Soviets provide the furnace, the various Comecon nationalities are responsible for the contents of the individual capsules and for working out the results-as well as for the symbolic code-name under which the experiment is performed.

This led, naturally, to the whole question of Comecon participation in manned space-flight. Hermaszewski stressed that, although he only knew the Czech and East German cosmonauts well-the other future crewmembers arrived only towards the end of his own training-he felt confident that all the countries concerned (even Mongolia and Cuba) would have their own "concepts" to contribute to the programme. "But obviously that's their secret for the moment." $\mathrm{He}$ alloys, of substances with very different

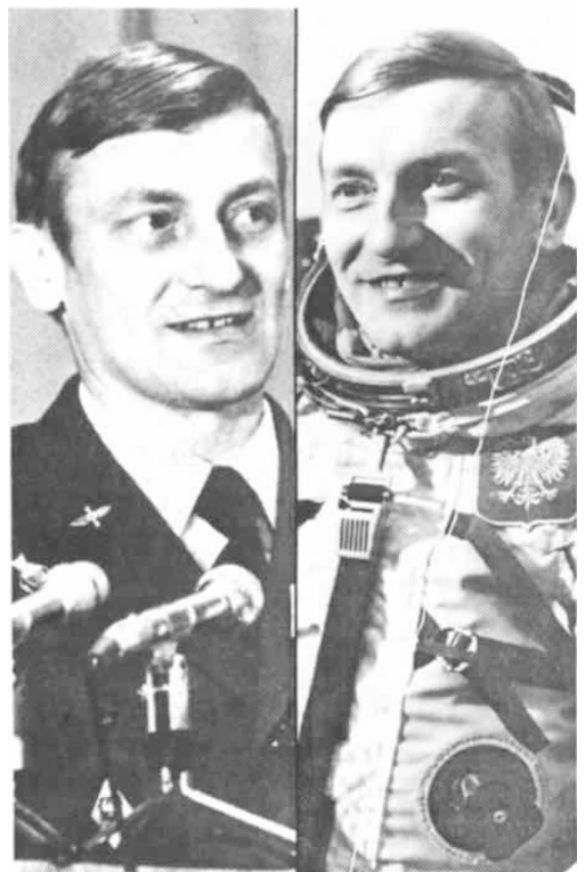

Two faces of Cosmonaut Hermaszewski; left-meeting the press; right, set for space.

stressed, moreover, that there are a number of joint experiments in the programme, for example, some of the photographic surveys, and such things as the joint Polish-Soviet experiment on heat level.

As for Poland's future plans in space, he was noncommittal. It was beyond his competence, he said, to comment on the future of the Interkosmos manned programme, when the present series of joint flights is complete, or on the possibility of wider international cooperation in space, perhaps on a UN basis. He stressed, however, that "We are only at the beginning of the Polish space programme."

Fields of special interest for the future included: "cosmic technology ('Syrena' was an example of this); space physics; and experiments with some immediate effect on our economy telecommunications, medicine, biology and so on".

As for his own future, Hermaszewski said that he is now doing a great deal of work with young people, including a special TV programme. "I have had a great many letters from the young people of our country, and they are all very proud that Poland has begun the peaceful exploration of space!" $\square$ 